\title{
Can Enterprise Architecture Be Based on the Business Strategy?
}

\author{
Svyatoslav Kotusev \\ HSE University \\ kotusev@kotusev.com
}

\author{
Sherah Kurnia \\ University of Melbourne \\ sherahk@unimelb.edu.au
}

\author{
Rod Dilnutt \\ University of Melbourne \\ rpd@unimelb.edu.au
}

\author{
Paul Taylor \\ DHHS Victoria \\ paul.taylor@dhhs.vic.gov.au
}

\begin{abstract}
Enterprise architecture (EA) is a set of documents describing various aspects of an organization from an integrated business and IT perspective. EA facilitates information systems planning and helps improve business and IT alignment. Traditionally, the concept of EA was closely coupled with the business strategy and mainstream EA methodologies recommend starting the EA effort from documenting the business strategy and then using it as the basis for defining the required structure of information systems. This conceptual paper discusses in detail four practical problems with the business strategy that question its value as the basis for EA initiatives. The presence of these problems challenges one of the most cherished beliefs or even axioms of the EA discipline: that EA should be based on the business strategy. This paper raises a number of questions regarding the information inputs necessary for the EA effort and calls for further research in respective directions.
\end{abstract}

\section{Introduction}

Nowadays the use of IT can be considered as essential for the business of many organizations. Companies invest a considerable amount of money in new IT systems and underlying infrastructure required to support their business operations. However, realizing the business value from these IT investments requires aligning, if not intertwining, business and IT strategies [1, 2, 3]. Enterprise architecture (EA) is a collection of organizational documents, typically called as artifacts, describing various aspects of an organization from an integrated business and IT perspective [4, 5]. EA intends to bridge the communication gap between business and IT stakeholders, facilitate information systems planning and thereby improve business and IT alignment $[6,7]$.

In the existing literature the concept of EA is very closely related to the business strategy. For instance, mainstream EA methodologies $[8,9,10,11]$ recommend starting EA initiatives from documenting the organizational business strategy, strategic vision, goals and objectives and then using this information further as the basis for defining the required structure of information systems. Some authors argue that EA should be derived directly from the top-level business strategy [12] or even propose the definitions of EA that explicitly reflect an inextricable link existing between EA and the business strategy [13]. Other authors go further and claim that there may be no EA without the business strategy [11, 14].

However, most claims on the fundamental importance of the business strategy for EA are purely prescriptive or highly speculative in nature and do not originate from evidence-based literature, while the broad analysis of empirically substantiated literature shows that the business strategy actually has a number of undesirable properties rendering it incongruous as the basis for EA initiatives. For example, in many organizations an articulate business strategy may be simply missing $[15,16]$, while in other organizations the business strategy may be extremely unstable and volatile $[17,18]$.

In this conceptual paper we answer the following research question: "What problems with the business strategy may prevent its use as the basis for EA and how can these problems be potentially addressed?" Specifically, we identify and discuss in detail four different practical problems with the business strategy found in literature that question its value as the potential basis for EA initiatives. This paper challenges the status quo in the EA discipline, disputes the central place of the business strategy in the EA discourse, raises a number of questions regarding the necessary inputs of the EA effort and calls for further research in respective directions.

Importantly, this paper does not intend to offer definite answers to the questions it raises, but rather to stimulate future research in order to clarify the actual role of the business strategy for EA and understand what other information might be required as an input for EA initiatives.

This paper continues as follows: (1) we discuss the perceived role of the business strategy for EA in the mainstream EA literature, (2) we discuss four problems 
with the business strategy identified in empirical literature that may prevent its use as the basis for EA, (3) we address the question whether EA can be actually based on the business strategy as prescribed in literature, (4) we discuss possible solutions to the identified problems, (5) we outline critical questions and directions for future EA research related to the business strategy, its value as the basis for EA and other possible inputs of the EA effort and (6) we conclude the paper and discuss the implications of our findings for research and practice.

\section{The role of the business strategy for enterprise architecture}

The term "business strategy" has numerous slightly different meanings and interpretations in literature [19]. However, it can be generally understood as "a combination of the ends (goals) for which the firm is striving and the means (policies) by which it is seeking to get there" $[20, \mathrm{p} . \mathrm{xvi}]^{1}$.

Traditionally, the notion of business strategy plays a significant role in the EA discourse and the business strategy is widely considered as a starting point, or basis, for developing EA artifacts defining the future structure of information systems required by the organization. In fact, all mainstream EA methodologies propose to start the development process of EA artifacts in some or the other form directly from the organizational business strategy, e.g. mission, vision, drivers, goals, objectives and key performance indicators (KPIs) [8, 9, 10, 11, 12, 21, 22, 23, 24, 25, 26, 27, 28].

For example, Holcman [25] recommends starting the EA effort from explicitly documenting the business goals and their hierarchy. van't Wout et al. [11, p. 35] list the business vision, mission, strategy, drivers and objectives as first EA artifacts of the contextual layer, which "sets the stake in the ground for the rest of the architecture by providing context". Similarly, TOGAF [10] lists the business strategy, goals and drivers among the primary inputs of the preliminary phase of its architecture development method (ADM). Bittler and Kreizman [12, p. 4] claim that "future-state EA is directly derived from business strategy" and argue that "the goal [of the EA effort] is to translate business strategy into a set of prescriptive guidance to be used by the organization (business and IT) in projects that implement change" [12, p. 7]. IBM's EA consulting

\footnotetext{
${ }^{1}$ The business strategy can also exist at different organizational levels, e.g. corporate, divisional and departmental. In this paper we discuss specifically the top-level corporate business strategy defined by $\mathrm{C}$-level executives. Our analysis and conclusions may not be equally applicable to more detailed lower-level strategies defined within separate business units
}

method states that EA is "driven by strategy" [27, p. 4]. Likewise, Oracle's EA framework declares that "driven by business strategy" is the first of its core values [26, p. 4]. Essentially, all these methodologies consider the business strategy as the core input for EA initiatives.

Analogous ideas regarding the primacy of the business strategy are also expressed by other authors [29, 30, 31, 32], who argue that EA and IT planning efforts in organizations should stem directly from the business strategy. Bernard [33, p. 12] states that "the idea of Enterprise Architecture is that of integrating strategy, business, and technology". Parker and Brooks $[34$, p. 46] argue that the business strategy and EA are interrelated so closely that they actually represent "the chicken or the egg" dilemma. These views are supported by Gartner as well, whose analysts even explicitly define EA as "the process of translating business vision and strategy into effective enterprise change" [13, p. 2]. Moreover, Gartner analysts argue that "the strategy analysis is the foundation of the EA effort" and propose six best practices to align EA with the business strategy [35, p. 1]. Unsurprisingly, similar views are also shared by academic researchers, who analyze the integration between the business strategy and EA [36], modeling of the business strategy in the EA context [37, 38, 39] as well as other aspects of their relationship $[40,41]$.

To summarize, in the existing EA literature the business strategy is widely considered as the necessary basis for EA and for many authors the very concepts of business strategy and EA are inextricably coupled, i.e. EA essentially cannot exist without the business strategy. Current views on the role of the business strategy for EA prevalent in literature can arguably be best summarized in the words of Schekkerman [14, p. 6], who formulates this idea in the most striking way: "No strategy, no enterprise architecture". van't Wout et al. [11, p. 11] echo the same view almost verbatim: "No strategy, no architecture. No vision, no architecture".

\section{Problems with the business strategy as the basis for enterprise architecture}

Despite the widespread acknowledgement of the guiding role of the business strategy for EA initiatives in the current EA literature, as discussed above, a number of important facts on the business strategy allow questioning its actual place in relation to EA. Interestingly, all the discussions of the relationship between the business strategy and EA are highly speculative, while all the claims on the importance of the business strategy for the EA effort are purely prescriptive. For instance, none of the publications 
cited in the previous section to highlight the central role of the business strategy in the EA discourse is based on empirical research in real organizations. All these publications are either purely conceptual, or at best based only on anecdotal evidence. At the same time, a broad analysis of the empirically substantiated literature on business and IT alignment, information systems planning and EA reveals the existence of at least four long-recognized major problems with the business strategy, which suggest that it actually cannot be considered as a sound basis for EA initiatives.

\subsection{Business strategy is often vague, unknown or merely absent}

Firstly, despite the prevalence of "no strategy, no architecture" thinking advocated, among others, by Schekkerman [14] and van't Wout et al. [11], many organizations actually face exactly this situation: they have no strategy, or at least no clear strategy ${ }^{2}$. Over the last decades numerous authors have consistently noticed that in many organizations the business strategy is very inarticulate, unknown to decisionmakers or simply absent altogether $[15,16,42,43,44$, $45,46,47,48,49,50,51,52,53,54,55,56,57,58,59$, $60]$.

The first observations regarding the absence of a formal business strategy and clear strategic plans in organizations had been made in the mid-1980s by Galliers [54], Lederer and Mendelow [43] and Vitale et al. [47]. For example, Lederer and Mendelow [46, p. 11] reported that "nine IS executives stated that sometimes top business executives have no clearly defined mission, objectives, and priorities, and do not know their plans for the coming year". Moreover, "some interviewees maintained that top [business] executives preferred flexibility which is lost when a plan is written" [56, p. 16]. Analogous conclusions had been reported by Vitale et al. [47, p. 268]: "Many IS managers would feel very fortunate to have a clear picture of where their organization is headed so that they could match IS and organization efforts. But many organizations have no well defined strategy"

During the 1990s similar findings had been reported by Baets [48], Bhide [59], Flynn and Hepburn [55], Sillince and Frost [60] and Segars and Grover [49]. For example, Baets [48, p. 206] reported that "preliminary research undertaken by the author in a

\footnotetext{
${ }^{2}$ Since the business strategy is not defined within EA initiatives, its presence or absence is considered as a given immutable condition for architects to which they need to adapt. Moreover, the absence of the business strategy does not necessarily represents a problem for organizations and in some cases may be even beneficial for business [19]. Generally, any discussions of the business strategy itself, its virtues and desirable qualities are out of the scope of this paper
}

well ranked European bank showed quite clearly that many of its middle managers, charged with carrying out the corporate strategy on behalf of the bank, were unable to define the corporate strategy". Likewise, the survey of 100 founders from the list of 500 fastest growing U.S. companies demonstrated that only $28 \%$ of them had formal business plans or strategies [59]. Sillince and Frost [60, p. 111] found that in public sector organizations clear strategies and goals might be absent for political reasons: "[In police] the business strategies of change have been less clear-cut in political terms; government has been ambivalent about them. [...] So police goals are not at all clear".

During the 2000s similar observations had been repeated by Hackney et al. [58], Rosser [53], Slater [57], Campbell [42] and Chan and Reich [50]. For example, Slater [57, p. 85] reported that the survey by Cutter Consortium found that "almost a third of the respondents had no formally articulated business plan at all". Campbell [42, p. 657] reported that "the results [of my study] indicate that the major concern of practitioners when considering alignment is coping with the ambiguity surrounding the business strategies that are actually in use". Chan and Reich [50, p. 299] noted that "a recurring issue seen in previous alignment research is that often corporate strategy is unknown [...] or, if known, is unclear and/or difficult to adapt".

More recently analogous observations have been repeated once again by Brown [15], Banaeianjahromi and Smolander [51] and Cantara et al. [52]. For example, Brown [15, p. 6] reports that "the espoused ideal was that there should be a clear business strategy on which to base [information systems planning, while] the practical reality was that very often business strategy was either intangible, not clear, or deliberately ambiguous for political reasons". The Gartner survey found that "two-thirds of business leaders are unclear about what their business strategy is and what underlying assumptions it is based on" [16, p. 2].

Therefore, the lack of a clear business strategy in many organizations that can be taken as the basis for further IT planning has been consistently reported by researchers since the 1980s. Unsurprisingly, the survey by Hauder et al. [61] shows that $84.8 \%$ of European and U.S. organizations consider unclear business goals as a significant challenge to their EA practices.

\subsection{Business strategy rarely provides a clear direction for IT}

Secondly, even when organizations have a rather articulate formal business strategy, this strategy often is still unable to provide a clear direction for IT. This problem with the business strategy has been also 
consistently noticed by many authors over the last decades [43, 44, 45, 46, 49, 56, 57, 62, 63, 64].

Initially, Lederer and Mendelow [44, p. 393], who studied difficulties in identifying business executives' objectives by IT planners, found that often "top management fails to communicate corporate objectives in a way to which IS personnel can relate". Specifically, Lederer and Mendelow [56, p. 16] clarified that "in other cases [when formal plans existed], the corporate plans were glittering generalities or mere financial targets which could not be translated into IT plans". As Lederer and Mendelow [44, p. 393] reported, the business strategy often defines some purely financial indicators useless for IT planning purposes: "For example, top management told one interviewee that the organization's major objective was to increase sales by a given percentage and that IS should provide systems to help do so. This provided little substantive direction as to what specific systems to develop". The same reasoning applies to market share and other similar goals as well: "For example, an objective to "increase market share by a specified percentage" does not define a computer application, leaving systems managers to draw their own, sometimes erroneous, conclusions" [45, p. 74]. Lederer and Mendelow [46, p. 11] also identified some more complex situations: "Finance Vice President stated that his objective was to "maximize the financial flexibility of the organization" but could not articulate how this should be done. This objective was too general to permit the [IT] director to formulate a supporting plan for [information systems]".

Later, Segars and Grover [49, p. 387] reported an analogous story: "Many IS planners noted that the strategic direction of the organization was not communicated in a manner which was understandable. In some instances strategic direction was communicated in terminology or documentation which was difficult to interpret". Likewise, Slater [57, p. 86] noted that "business strategies are typically written at a very high level. They frequently talk about markets, sales and distribution channels, and growth targets, but rarely address how the company gets its work done". As Ross et al. [64, p. 6] put it, "general statements about the importance of "leveraging synergies" or "getting close to the customer" are difficult [for IT] to implement".

Therefore, the problem with formulating business strategies and plans in a way that does not provide any clear actionable suggestions for IT has been recognized by researchers for a long time. This problem also questions the value of the business strategy as the basis for EA initiatives.

\subsection{Business strategy is often unstable and frequently changes}

Thirdly, even when organizations have a rather clear and actionable business strategy, this strategy is often unstable, frequently changing and unable to provide a steady basis for planning IT. This problem with the business strategy is also consistently noticed by many authors over the last decades $[17,18,44,45$, 46, 47, 49, 62, 64, 65, 66].

For example, Lederer and Mendelow [46, p. 11] noticed long ago that "even if top executives know their plans in sufficient detail, an unstable environment might render them inapplicable". Later, Lederer and Mendelow [66] studied the problem of shifting priorities in more detail and identified the inherent instability of the business strategy due to the fickleness of the marketplace, changing customer needs and corporate acquisitions as a major factor contributing to this problem. As noted by one of the interviewed IT executives, "the winds change with each quarterly director's meeting and we come back with a new set of signals" [66, p. 323].

Segars and Grover [49] also identified the instability of the business strategy as one of the risk factors of architectural planning. For instance, an architect of a large U.S. financial organization vividly illustrated this problem: "We did a thorough job of aligning ourselves with organizational strategy. We felt confident in our analysis and proceeded to operate within the enterprise models developed. However, we did not do a good enough job of ensuring that these models were maintained. It only took a period of months before critical aspects of strategy and the business had changed" [49, p. 388].

Sauer and Willcocks $[65$, p. 41] reported that "most [surveyed CEOs and CIOs from 97 e-business companies] were responding to an increasingly volatile business environment by shrinking their development and planning cycles. Half don't extend plans beyond a year, and half of those with infrastructure plans update them quarterly". Likewise, significant environmental uncertainly and constant changes in the business strategy are also typical for companies in the retail industry sector. For example, an architect from a major retail company vividly illustrates this situation: "The problem with an organization like this is that in twelve months the organization has changed direction three or four times. So, you're not going to get that kind of stability that fits those timeframes" [17, p. 34].

The inability of the business strategy to offer a stable foundation for EA initiatives is reported by reflective EA practitioners as well: "It is therefore a fundamental flaw in many enterprise architecture approaches that one starts from the (current) business 
strategy and/or a set of principles that may be derived from that strategy. Such a waterfall almost never works. [Although strategy should be taken into account,] simply taking the current strategy and hand that to the architects to turn it into the starting point of enterprise architecture will almost certainly fail, because the strategy is going to change long before the results of enterprise architecture are visible" [18, pp. 141-142].

Therefore, the instability of the business strategy in many organizations for the purposes of architectural planning has been also consistently reported by researchers and practitioners since the 1980s. Unsurprisingly, the survey by Hauder et al. [61] shows that $71.4 \%$ of European and U.S. organizations consider quickly changing organizational environment as a significant challenge for their EA practices.

\subsection{Business strategy often requires strategy- specific, non-reusable IT systems}

Finally, even when organizations have a rather clear, actionable and stable business strategy, this strategy often requires highly specific, non-reusable IT systems that cannot deliver lasting business value beyond the current strategy. This problem with the business strategy is recognized less widely than the three other problems discussed earlier, but is still acknowledged by a number of authors $[18,62,63,64$, 67, 68, 69, 70].

After being developed and deployed, information systems typically exist in organizations much longer than the business strategies or strategic initiatives they were intended to support [64, 69, 70]. Specifically, "average" business strategies may be active for the period of no longer than 3-5 years, while the IT systems created to execute these strategies may stay in organizations for 10-15 years or even longer [69, 70]. For instance, Mocker [70] explains this mismatch metaphorically by saying that IT exists in a different "time zone" from the business.

For this reason, even a stable business strategy is unable to provide a long-lasting, sustainable view of the business commensurable with the lifespan of its information systems and enable the proactive use of IT in the organization in the long run. As a result, "IT is left to align with individual strategic initiatives - after they are announced. Thus, IT becomes a persistent bottleneck" [62, p. 1]. These attempts to chase everchanging business strategies (ever-changing in a sense that even rather stable strategies active for the period of 3-5 years can change faster and more radically than information systems, which often stay active for the longer period of 10-15 years) usually lead to the proliferation of legacy IT systems in organizations that once were strategic, but then lost their relevance to the business [64, 69]. Thereby, today's IT assets often become tomorrow's IT burden.

For example, Shpilberg et al. [67, p. 52] call such situations, when strategically aligned information systems eventually turn into an inefficient, entangled and fragile IT landscape, as "alignment traps" and describe one of these situations in the following way: "The company's various divisions were driving independent initiatives, each one designed to address its own competitive needs. IT's effort to satisfy its various (and sometimes conflicting) business constituencies created a set of Byzantine, overlapping systems that might satisfy individual units for a while but did not advance the company's business as a whole". Similarly, Weill and Ross [63, p. 1] describe this situation in the following way: "IT organizations attempt to build capabilities while addressing a laundry list of immediate business needs. The result, in most cases, is IT spaghetti - with ever increasing maintenance costs and slow time to market".

The inability of the business strategy to offer a long-term guidance (comparable to the typical 10-15 years lifespan of information systems) regarding the required structure of the organizational IT landscape is recognized by reflective EA practitioners as well. For instance, Wierda [18, p. 134] argues that "what people seldom realize that if you build a landscape of elements that have an average life span of fifteen years with a strategy that changes direction every few years, chances are that you end up with a mess". "Ironically, one of the most pregnant uncertainties is the strategy of the company itself. Systems have an average life time of fifteen years. The strategy of a company [on average remains constant for only] maybe four. In other words: in the time that the architecture of a system and a large part of its surrounding systems exists, the organization's strategy will have changed four times, and often such changes are pretty radical" [18, pp. 140141].

Therefore, the unsuitability of the business strategy as the foundation for a long-range architectural planning exceeding the horizon of 3-5 years is also acknowledged by both researchers and practitioners. The ensuing susceptibility to "alignment traps" questions the value of the business strategy as the basis for EA initiatives.

\section{Can enterprise architecture be based on the business strategy?}

The four problems with the business strategy discussed above suggest that the business strategy either cannot be taken as the basis for EA initiatives at all due to its absence, vagueness or volatility, or at best 
can provide only some relatively short-term direction for IT incommensurable with the typical lifespan of information systems in organizations. A conceptual decision-making framework for assessing the possibility of using the business strategy as the basis for EA reflecting the four common problems highlighted in this study is shown schematically in Figure 1.

The existence and widespread acknowledgement of the four problems with the business strategy shown in Figure 1 suggests that contrary to the popular claims found in popular prescriptive literature, the business strategy actually can hardly provide any real practical basis for EA, or at least the business strategy taken alone on its own. In light of these findings, the tenet that EA should be derived directly from the business strategy or rooted in strategic drivers, goals and objectives advocated by most EA methodologies [8, 9, $10,11,12,21,22,23,24,25,26,27,28]$ can be considered more as an attractive cliché or seductive motto, than as a realistic actionable prescription that can be successfully implemented in practice.

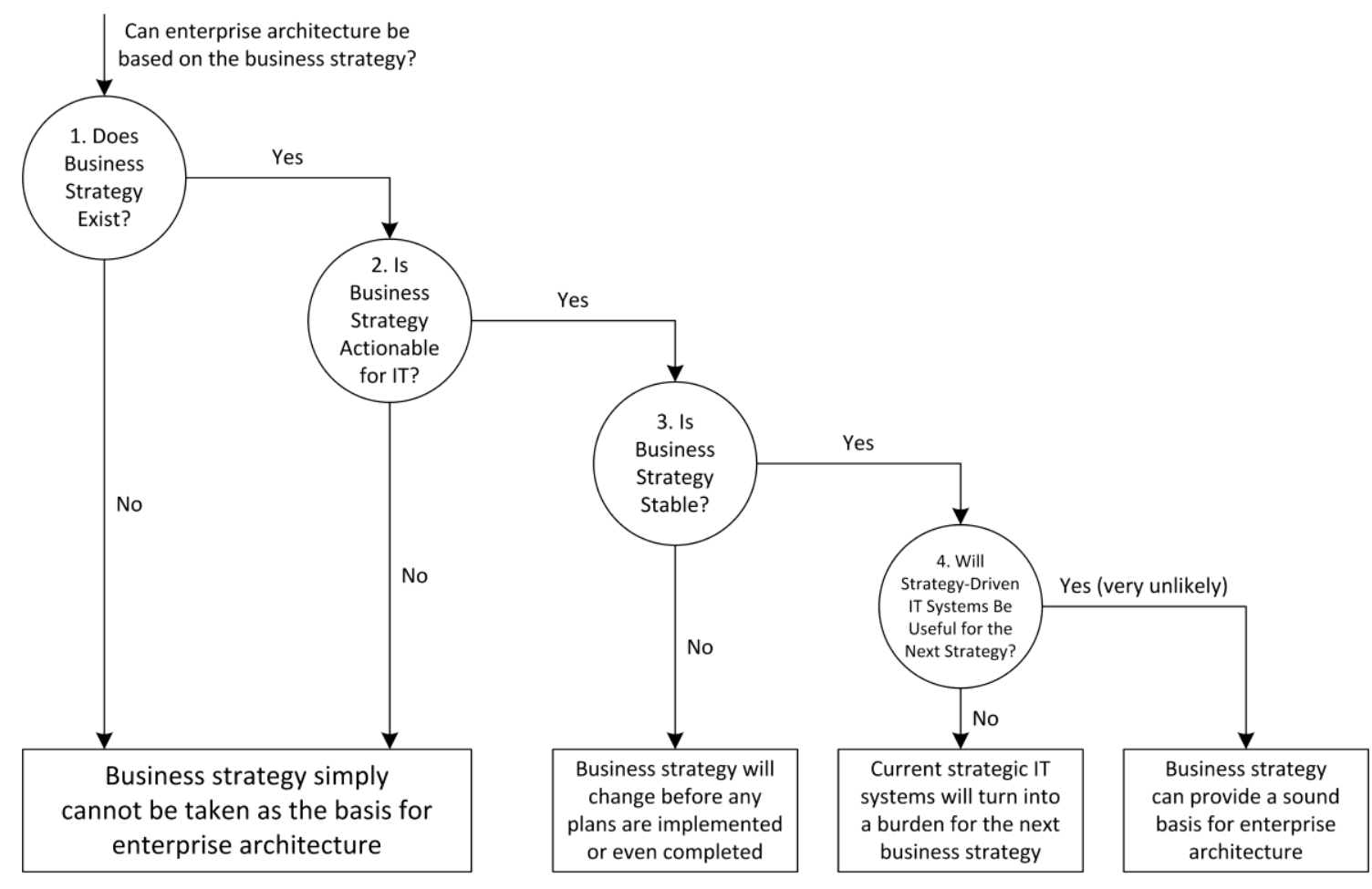

Figure 1. Assessment of the business strategy as the basis for enterprise architecture

\section{Possible solutions to the identified problems}

Although the problems with the business strategy discussed above (see Figure 1) have no definite answers in the available EA literature, some approaches still seem promising as potential solutions to these problems. These approaches can be grouped into conceptual, organizational and technical ones.

Conceptually, some other aspects of organizations might be taken as an input for EA initiatives. For example, Ross et al. [64, p. 25] recommend to use an operation model (i.e. "the necessary level of business process integration and standardization for delivering goods and services to customers") as the basis for planning IT. Unlike the business strategy, an operating model should always exist in some or the other form, should be more clear, actionable for IT and stable in the long run [62, 64]. However, this suggestion is highly prescriptive, received only a limited independent validation [71, 72] and it is still largely unclear whether, to what extent and how many organizations actually find the concept of operating model helpful for their IT planning efforts.

Organizationally, some problems with the business strategy might be resolved though establishing effective IT governance arrangements and a closer dialog between business and IT helping intertwine business and IT strategies together. For example, the IT governance literature stresses the importance of collaborative decision-making involving both business and IT leaders with clearly defined responsibilities and 
decision rights $[68,73]$. Similarly, the importance of direct communication and finding a common language between business and IT stakeholders has been long recognized in the business and IT alignment literature $[46,50,74,75]$. However, the details of respective processes (e.g. what planning decisions get made, who makes them and when as well as how exactly the business strategy is converted into IT actions) still remain insufficiently understood [76].

Technically, the problem of the instability of the business strategy in the short and long terms might be alleviated via adopting agile delivery approaches and flexible architectural paradigms (e.g. service-oriented architecture) respectively. In particular, agile techniques may promote better adaptability to rapidly changing business needs, while service-oriented architecture may facilitate higher reuse of the accumulated IT assets in future business strategies. However, these approaches address only some problems with the business strategy and may not offer a "complete" solution.

\section{Directions for future research}

The four problems with the business strategy identified and presented in this paper (see Figure 1) challenge the status quo in EA research and question one of the most cherished beliefs, assumptions or even axioms of the EA discipline: that EA should be based on the business strategy. As demonstrated in this paper, these beliefs are based essentially only on the recommendations of prescriptive EA methodologies promoted by consultancies and gurus $[8,9,10,11,12$,
$21,22,23,24,25,26,27,28]$ and on some other EA literature which is either completely speculative, or substantiated only by anecdotal evidence $[13,14,29$, $30,31,32,33,34,35,36,37,38,39,40,41]$. At the same time, all the potential solutions to these problems outlined earlier are only tentative, somewhat speculative and none of them has been thoroughly studied and validated in the EA context.

These inconsistencies between the current assumptions of the EA discipline and the actual empirical realities in organizations raise a number of important questions that help shape future directions for EA research. Essentially, these questions can be roughly reduced to two distinct broad questions and respective research directions. The first question can be formulated as follows: "What is the actual role of the business strategy in EA initiatives?". The second question can be formulated as follows: "What other inputs are necessary or desirable for EA initiatives?"

The meaning of these two questions can be illustrated schematically as an intersection of the business strategy and valuable input for EA, where some elements of the business strategy can be considered as irrelevant for EA, other elements of the business strategy can be considered as valuable for EA, while some other information unrelated to it can be also considered as valuable for EA. The resulting intersection diagram is shown in Figure 2.

The two questions discussed above have no definite answers in the existing EA literature. Both of them can arguably be considered as critical for the EA discipline, deserve further investigation and may provide fruitful directions for future EA research.

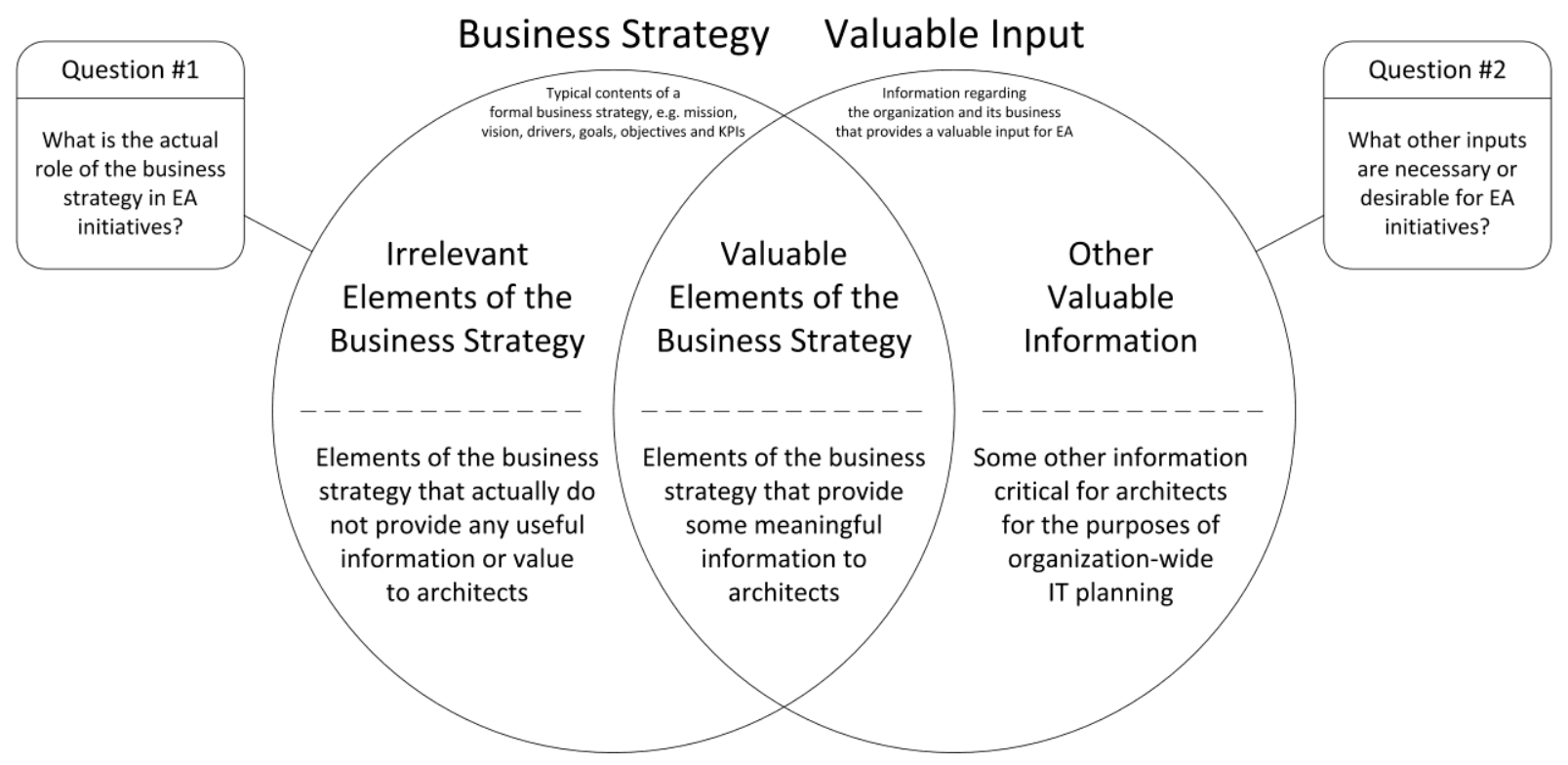

Figure 2. Proposed questions to guide future research on the basis for EA 


\section{Conclusion}

Contrary to the claims on the critical importance of the business strategy for EA teeming in the available prescriptive and conceptual literature, an empirically substantiated analysis of the problems associated with the business strategy questions its actual significance and value as an input for EA initiatives. This inconsistency between the assumed and actual roles of the business strategy for EA initiatives can be regarded as one of the most critical questions in EA research [77].

At the same time, the existing EA literature does not provide any clear suggestions regarding what other information might be necessary or desirable for EA initiatives. Due to the evident theoretical and practical importance of these gaps, addressing the questions proposed in this paper can be considered as a worthwhile direction for future research in the EA discipline.

This study has important implications for both EA research and practice. From the research perspective, our findings suggest that EA scholars cannot conceptualize EA as a derivative from the business strategy and cannot reasonably assume that the business strategy provides a critical input for EA initiatives. The realities of EA seem to be more complex than it is widely believed.

From the practical perspective, our findings suggest that EA practitioners should seek some other additional information regarding the organization and its business that would be more helpful for the EA effort than the business strategy. In other words, architects should find alternative discussion points with their business colleagues to be able to plan corporate information systems in a meaningful way.

One of the study limitations is that the references supporting the four problems discussed in this paper are dispersed across a very broad body of EA and other related literature. For this reason, some other potential problems with the business strategy might have been missed or unnoticed by the authors. Furthermore, this study is purely conceptual and does not leverage any first-hand empirical data to investigate the four identified problems in greater detail. Nevertheless, we believe this paper raises an important issue which is likely to provoke further research and advance the EA discipline forward.

\section{Acknowledgement}

We would like to thank the Australian Research Council for funding this study (DP14010024).

\section{References}

[1] Henderson, J.C., and Venkatraman, N., "Strategic Alignment: Leveraging Information Technology for Transforming Organizations", IBM systems journal, 32(1), 1993, pp. 4-16.

[2] Byrd, T.A., Lewis, B.R., and Bryan, R.W., "The Leveraging Influence of Strategic Alignment on IT Investment: An Empirical Examination", Information and Management, 43(3), 2006, pp. 308-321.

[3] Gerow, J.E., Grover, V., Thatcher, J.B., and Roth, P.L., "Looking Toward the Future of IT-Business Strategic Alignment Through the Past: A Meta-Analysis", MIS quarterly, 38(4), 2014, pp. 1059-1085.

[4] Kotusev, S., "Enterprise Architecture and Enterprise Architecture Artifacts: Questioning the Old Concept in Light of New Findings", Journal of Information technology, 34(2), 2019, pp. 102-128.

[5] Niemi, E., and Pekkola, S., "Using Enterprise Architecture Artefacts in an Organisation", Enterprise Information Systems, 11(3), 2017, pp. 313-338.

[6] Tamm, T., Seddon, P.B., Shanks, G., Reynolds, P., and Frampton, K.M., "How an Australian Retailer Enabled Business Transformation Through Enterprise Architecture", MIS Quarterly Executive, 14(4), 2015, pp. 181-193.

[7] Kotusev, S., The Practice of Enterprise Architecture: A Modern Approach to Business and IT Alignment, SK Publishing, Melbourne, Australia, 2018.

[8] Spewak, S.H., and Hill, S.C., Enterprise Architecture Planning: Developing a Blueprint for Data, Applications and Technology, Wiley, New York, NY, 1992.

[9] Bernard, S.A., An Introduction to Enterprise Architecture, AuthorHouse, 1st edn, Bloomington, IN, 2004.

[10] TOGAF, "TOGAF Version 9.2", C182, The Open Group, Reading, UK, 2018,

[11] van't Wout, J., Waage, M., Hartman, H., Stahlecker, M., and Hofman, A., The Integrated Architecture Framework Explained: Why, What, How, Springer, Berlin, 2010.

[12] Bittler, R.S., and Kreizman, G., "Gartner Enterprise Architecture Process: Evolution 2005", G00130849, Gartner, Stamford, CT, 2005, pp. 1-12.

[13] Lapkin, A., Allega, P., Burke, B., Burton, B., Bittler, R.S., Handler, R.A., James, G.A., Robertson, B., Newman, D., Weiss, D., Buchanan, R., and Gall, N., "Gartner Clarifies the Definition of the Term 'Enterprise Architecture'", G00156559, Gartner, Stamford, CT, 2008, pp. 1-5.

[14] Schekkerman, J., "Extended Enterprise Architecture Framework Essentials Guide, Version 1.5", Institute for Enterprise Architecture Developments (IFEAD), Amersfoort, The Netherlands, 2006,

[15] Brown, I., "Strategic Information Systems Planning: Comparing Espoused Beliefs with Practice", Proceedings of the 18th European Conference on Information Systems, 2010, pp. 1-12. 
[16] Cantara, M., Burton, B., and Scheibenreif, D., "Eight Best Practices for Creating High-Impact Business Capability Models", G00314568, Gartner, Stamford, CT, 2016, pp. 113 .

[17] Kotusev, S., Singh, M., and Storey, I., "Enterprise Architecture Practice in Retail: Problems and Solutions", Journal of Enterprise Architecture, 12(3), 2016, pp. 28-39.

[18] Wierda, G., Chess and the Art of Enterprise Architecture, R\&A, Amsterdam, 2015.

[19] Mintzberg, H., Ahlstrand, B., and Lampel, J., Strategy Safari: A Guided Tour Through the Wilds of Strategic Management, The Free Press, New York, 1998.

[20] Porter, M.E., Competitive Strategy: Techniques for Analyzing Industries and Competitors, The Free Press, New York, NY, 1980.

[21] Theuerkorn, F., Lightweight Enterprise Architectures, Auerbach Publications, Boca Raton, FL, 2004.

[22] Niemann, K.D., From Enterprise Architecture to IT Governance: Elements of Effective IT Management, Vieweg, Wiesbaden, 2006.

[23] Longepe, C., The Enterprise Architecture IT Project: The Urbanisation Paradigm, Kogan Page Science, London, 2003.

[24] Carbone, J.A., IT Architecture Toolkit, Prentice Hall, Upper Saddle River, NJ, 2004.

[25] Holcman, S.B., Reaching the Pinnacle: A Methodology of Business Understanding, Technology Planning, and Change, Pinnacle Business Group Inc., Pinckney, MI, 2013.

[26] Covington, R., and Jahangir, H., "The Oracle Enterprise Architecture Framework", Oracle, Redwood Shores, CA, 2009,

[27] IBM, "An Introduction to IBM's Enterprise Architecture Consulting Method", IBM Global Services, Armonk, NY, 2006, pp. 1-17.

[28] Schekkerman, J., Enterprise Architecture Good Practices Guide: How to Manage the Enterprise Architecture Practice, Trafford Publishing, Victoria, BC, 2008.

[29] Finkelstein, C., Enterprise Architecture for Integration: Rapid Delivery Methods and Technologies, Artech House, Boston, MA, 2006.

[30] Perks, C., and Beveridge, T., Guide to Enterprise IT Architecture, Springer, New York, NY, 2003.

[31] Aitken, C., "Enterprise Architecture, Strategic Management, and Information Management", in (Doucet, G., Gotze, J., Saha, P., and Bernard, S., 'eds.'): Coherency Management: Architecting the Enterprise for Alignment, Agility and Assurance, AuthorHouse, Bloomington, IN, 2009, pp. 121-155.

[32] Pham, T., Pham, D.K., and Pham, A., From Business Strategy to Information Technology Roadmap: A Practical Guide for Executives and Board Members, Productivity Press, Boca Raton, FL, 2016.

[33] Bernard, S.A., "Using Enterprise Architecture to Integrate Strategic, Business, and Technology Planning", Journal of Enterprise Architecture, 2(4), 2006, pp. 11-28.
[34] Parker, T., and Brooks, T., "Which Comes First, Strategy or Architecture?", Journal of Enterprise Architecture, 4(4), 2008, pp. 46-57.

[35] Lapkin, A., "Six Best Practices for Aligning Enterprise Architecture with the Business Strategy", G00164923, Gartner, Stamford, CT, 2009, pp. 1-6.

[36] Aldea, A., Iacob, M.-E., Quartel, D., and Franken, H., "Strategic Planning and Enterprise Achitecture", Proceedings of the 1st Enterprise Systems Conference, 2013, pp. 1-8.

[37] Kitsios, F., and Kamariotou, M., "Business Strategy Modelling Based on Enterprise Architecture: A State of the Art Review", Business Process Management Journal, Online(Online), 2018, pp. 1-19.

[38] Iacob, M.-E., Quartel, D., and Jonkers, H., "Capturing Business Strategy and Value in Enterprise Architecture to Support Portfolio Valuation", Proceedings of the 16th IEEE International Enterprise Distributed Object Computing Conference, 2012, pp. 11-20.

[39] Aldea, A., Iacob, M.-E., and Quartel, D., "From Business Strategy to Enterprise Architecture and Back", Proceedings of the 13th Trends in Enterprise Architecture Research Workshop, 2018, pp. 145-152.

[40] van Gils, B., "Strategy and Architecture - Reconciling Worldviews", Proceedings of the 1st Working Conference on Practice-Driven Research on Enterprise Transformation, 2009, pp. 181-196.

[41] Bhattacharya, P., "Aligning Enterprise Systems Capabilities with Business Strategy: An Extension of the Strategic Alignment Model (SAM) Using Enterprise Architecture", Proceedings of the 24th Americas Conference on Information Systems, 2018, pp. 1-10.

[42] Campbell, B., "Alignment: Resolving Ambiguity within Bounded Choices", Proceedings of the 9th Pacific Asia Conference on Information Systems, 2005, pp. 656-669.

[43] Lederer, A.L., and Mendelow, A.L., "Paradoxes of Information Systems Planning", Proceedings of the 7th International Conference on Information Systems, 1986, pp. 255-264.

[44] Lederer, A.L., and Mendelow, A.L., "Information Resource Planning: Overcoming Difficulties in Identifying Top Management's Objectives ", MIS quarterly, 11(3), 1987, pp. 389-399.

[45] Lederer, A.L., and Mendelow, A.L., "Information Systems Planning: Top Management Takes Control", Business Horizons, 31(3), 1988, pp. 73-78.

[46] Lederer, A.L., and Mendelow, A.L., "Coordination of Information Systems Plans with Business Plans", Journal of Management Information Systems, 6(2), 1989, pp. 5-19.

[47] Vitale, M.R., Ives, B., and Beath, C.M., "Linking Information Technology and Corporate Strategy: An Organizational View", Proceedings of the 7th International Conference on Information Systems, 1986, pp. 265-276.

[48] Baets, W.R.J., "Aligning Information Systems with Business Strategy", Journal of Strategic Information Systems, 1(4), 1992, pp. 205-213. 
[49] Segars, A.H., and Grover, V., "Designing CompanyWide Information Systems: Risk Factors and Coping Strategies", Long Range Planning, 29(3), 1996, pp. 381-392.

[50] Chan, Y.E., and Reich, B.H., "IT Alignment: What Have We Learned?", Journal of Information technology, 22(4), 2007, pp. 297-315.

[51] Banaeianjahromi, N., and Smolander, K., "Understanding Obstacles in Enterprise Architecture Development", Proceedings of the 24th European Conference on Information Systems, 2016, pp. 1-15.

[52] Cantara, M., Burton, B., Weldon, L., and Scheibenreif, D., "Three Things CIOs Can Say to Get CEOs Excited About Business Capability Modeling", G00320029, Gartner, Stamford, CT, 2016, pp. 1-15.

[53] Rosser, B., "IT Planning: How to Elicit a Business Strategy", TU-11-8194, Gartner, Stamford, CT, 2000, pp. 14.

[54] Galliers, R.D., "A Failure of Direction", Business Computing and Communications, 5(7), 1986, pp. 32-38.

[55] Flynn, D.J., and Hepburn, P.A., "Strategic Planning for Information Systems - A Case Study of a UK Metropolitan Council", European Journal of Information Systems, 3(3), 1994, pp. 207-217.

[56] Lederer, A.L., and Mendelow, A.L., "Information Systems Planning: Incentives for Effective Action", DATA BASE for Advances in Information Systems, 20(3), 1989, pp. 13-20.

[57] Slater, D., "Strategic Planning Don'ts (and Dos): As You Write Your Company's Next IT Strategic Plan Don't Repeat These Classic Mistakes", CIO Magazine, 15(16), 2002, pp. 84-93.

[58] Hackney, R., Burn, J., and Dhillon, G., "Challenging Assumptions for Strategic Information Systems Planning: Theoretical Perspectives", Communications of the Association for Information Systems, 3(3), 2000, pp. 1-24.

[59] Bhide, A., "How Entrepreneurs Craft Strategies That Work", Harvard Business Review, 72(2), 1994, pp. 150-161.

[60] Sillince, J.A.A., and Frost, C.E.B., "Operational, Environmental and Managerial Factors in Non-Alignment of Business Strategies and IS Strategies for the Police Service in England and Wales", European Journal of Information Systems, 4(2), 1995, pp. 103-115.

[61] Hauder, M., Roth, S., Matthes, F., and Schulz, C., "An Examination of Organizational Factors Influencing Enterprise Architecture Management Challenges", Proceedings of the 21st European Conference on Information Systems, 2013, pp. 1-12.

[62] Ross, J.W., "Forget Strategy: Focus IT on Your Operating Model", Center for Information Systems Research (CISR), MIT Sloan School of Management, Cambridge, MA, 2005 ,

[63] Weill, P., and Ross, J.W., "Implementing Your Operating Model Via IT Governance", Center for
Information Systems Research (CISR), MIT Sloan School of Management, Cambridge, MA, 2008,

[64] Ross, J.W., Weill, P., and Robertson, D.C., Enterprise Architecture as Strategy: Creating a Foundation for Business Execution, Harvard Business School Press, Boston, MA, 2006.

[65] Sauer, C., and Willcocks, L.P., "The Evolution of the Organizational Architect", MIT Sloan Management Review, 43(3), 2002, pp. 41-49.

[66] Lederer, A.L., and Mendelow, A.L., "Information Systems Planning and the Challenge of Shifting Priorities", Information and Management, 24(6), 1993, pp. 319-328.

[67] Shpilberg, D., Berez, S., Puryear, R., and Shah, S., "Avoiding the Alignment Trap in Information Technology", MIT Sloan Management Review, 49(1), 2007, pp. 51-58.

[68] Weill, P., and Ross, J.W., IT Savvy: What Top Executives Must Know to Go from Pain to Gain, Harvard Business School Press, Boston, MA, 2009.

[69] Ross, J.W., "Gaining Competitive Advantage from Enterprise Architecture (Executive Seminar: Enabling IT Value Through Enterprise Architecture)", 2011, https://www.youtube.com/watch?v=ScHG63YmJ2k\&t=572, accessed 18 June, 2017.

[70] Mocker, M., "2012-07 Enterprise Architecture Research at MIT", 2012, https://www.youtube.com/watch?v=9IGQm4HheA, accessed 18 June, 2017.

[71] Kiat, S.E., Chiew, L.H., Hong, P.S., and Fung, C.C., "The Organization's Compass - Enterprise Architecture", Journal of Enterprise Architecture, 4(1), 2008, pp. 11-19.

[72] de Vries, M., and van Rensburg, A.C.J., "Evaluating and Refining the 'Enterprise Architecture as Strategy' Approach and Artifacts", South African Journal of Industrial Engineering, 20(1), 2009, pp. 31-43.

[73] Weill, P., and Ross, J.W., IT Governance: How Top Performers Manage IT Decision Rights for Superior Results, Harvard Business School Press, Boston, MA, 2004.

[74] Reich, B.H., and Benbasat, I., "Factors that Influence the Social Dimension of Alignment Between Business and Information Technology Objectives", MIS quarterly, 24(1), 2000, pp. 81-113.

[75] Wagner, H.-T., Beimborn, D., and Weitzel, T., "How Social Capital Among Information Technology and Business Units Drives Operational Alignment and IT Business Value", Journal of Management Information Systems, 31(1), 2014, pp. 241-272.

[76] Karpovsky, A., and Galliers, R.D., "Aligning in Practice: From Current Cases to a New Agenda", Journal of Information technology, 30(2), 2015, pp. 136-160.

[77] Kotusev, S., "Critical Questions in Enterprise Architecture Research", International Journal of Enterprise Information Systems, 13(2), 2017, pp. 50-62. 